\title{
River fragmentation increases localized population genetic structure and enhances asymmetry of dispersal in bullhead (Cottus gobio)
}

\author{
Julian Junker • Armin Peter • Catherine E. Wagner • \\ Salome Mwaiko • Brigitte Germann • \\ Ole Seehausen • Irene Keller
}

Received: 30 March 2011/Accepted: 15 December 2011/Published online: 29 January 2012

(C) Springer Science+Business Media B.V. 2012

\begin{abstract}
Man-made habitat fragmentation is a major concern in river ecology and is expected to have particularly detrimental effects on aquatic species with limited dispersal abilities, like the bullhead (Cottus gobio). We used ten microsatellite markers to investigate small-scale patterns of gene flow, current dispersal and neutral genetic diversity in a morphologically diverse river where fragmented and unfragmented sections could be compared. We found high genetic differentiation between sampling sites with a maximum $F_{\mathrm{ST}}$ of 0.32 between sites separated by only $35 \mathrm{~km}$. A significant increase of genetic differentiation with geographical distance was observed in the continuous river section as well as in the full dataset which included
\end{abstract}

Electronic supplementary material The online version of this article (doi:10.1007/s10592-011-0306-x) contains supplementary material, which is available to authorized users.

J. Junker $(\bowtie) \cdot$ A. Peter · C. E. Wagner · S. Mwaiko ·

B. Germann · O. Seehausen · I. Keller

Center of Ecology, Evolution and Biochemistry, Department of Fish Ecology and Evolution, EAWAG Swiss Federal Institute of Aquatic Science and Technology, Seestrasse 79, 6047

Kastanienbaum, Switzerland

e-mail: julian.junker@eawag.ch

J. Junker · O. Seehausen

Department of Aquatic Ecology and Macroevolution, Institute of Ecology and Evolution, University of Bern, Baltzerstrasse 6, 3012 Bern, Switzerland

C. E. Wagner

Department of Ecology and Evolutionary Biology, Corson Hall, Cornell University, Ithaca, NY 14853, USA

I. Keller

Department of Aquatic Ecology, EAWAG Swiss Federal Institute of Aquatic Science and Technology, Überlandstrasse 133, 8600 Dübendorf, Switzerland headwater populations isolated by anthropogenic barriers. Several lines of evidence are consistent with the hypothesis that such barriers completely block upstream movement while downstream dispersal may be little affected. In the unfragmented habitat, dispersal rates were also higher in the direction of water flow than against it. The resulting asymmetry in gene flow likely contributes to the decrease of genetic variation observed from the lower reaches towards the headwaters, which is particularly pronounced in physically isolated populations. Our findings suggest that headwater populations, due to their isolation and low genetic variation, may be particularly vulnerable to extinction.

Keywords Fragmentation - Microsatellites - Bullhead . Cottus gobio $\cdot$ Population genetic structure $\cdot$ Conservation

\section{Introduction}

Humans often alter the environment for their own benefit, to the detriment of other species sharing the same habitat. These alterations often result in fragmentation and loss of habitable area (Segelbacher et al. 2010) and an associated reduction in connectivity among populations (Kindlmann and Burel 2008). Together, these factors may cause population declines and, ultimately, species extinctions (Frankel and Soule 1981; Sala et al. 2000; Rosenzweig 2001).

Human-caused fragmentation in rivers is of major ecological concern (Raeymaekers et al. 2009). Rivers are frequently altered by the construction of hydroelectric dams, and by canalization for flood protection and control over water velocity. In Switzerland, the number of artificial barriers with a height of more than $0.5 \mathrm{~m}$ is estimated at around 101,000 , which amounts to 1.6 artificial barriers per 
kilometer of a river (Zeh et al. 2009). Such barriers likely affect the migration behavior of many aquatic species. Upstream migration is particularly likely to be affected, which may lead to isolation of populations in the head reaches of a river (Letcher et al. 2007).

The bullhead (Cottus gobio) is an ideal species to investigate the effects of river fragmentation on aquatic organisms. In contrast with many other fish species, it has little economical value and its population structure should be relatively unaffected by human activities, in particular artificial stocking (Englbrecht et al. 2000). Behavioral experiments showed a polygynous mating system where females choose the males based on size, and the males tend and guard the nest, which has eggs from several females (Bisazza and Marconato 1988). Such a mating system could lead to an effective population size $\left(\mathrm{N}_{\mathrm{e}}\right)$ which is much smaller than the census population size. The species has a reduced swim bladder and is morphologically adapted to a benthic lifestyle (Gaudin and Caillere 1990; Gädtgens 1989). Consistent with this potentially low dispersal ability, population genetic analyses have confirmed that, at the scale of entire drainage systems, bullhead populations are highly differentiated (Nolte et al. 2005a; Hänfling and Weetman 2006; Vonlanthen et al. 2007). Based on mark-recapture studies, the species has been classified as largely resident, only moving from 10 to several hundred meters a year (Smyly 1957; Andreasson 1971; Downhower et al. 1990; Knaepkens et al. 2004a), and as unable to pass barriers with a height above $20 \mathrm{~cm}$ (Utzinger et al. 1998). Detrimental effects of river fragmentation are therefore expected to be particularly pronounced and easily detectable (Bless 1981, 1990; Barandun 1990; Hofer and Bucher 1991; Jungwirth 1996; Knaepkens et al. 2002, 2004b; Tudorache et al. 2008).

An additional reason to investigate contemporary population genetic structure in bullheads is provided by reports of recent population declines in Switzerland. Bullhead populations have been negatively affected by environmental pollution (Starmach 1965; Späh and Beisenherz 1984; Bucher et al. 1992; Waterstraat 1992), and after local die-outs, only fish species with economical value were reintroduced (Barandun 1990; Hofer and Bucher 1991). In some instances, bullheads were even actively eradicated as they were thought to prey on the eggs and young of economically valuable trouts (Adamicka 1979, 1984; Gaudin and Heland 1984; Späh and Beisenherz 1984; Gaudin 1985). Together, these factors have contributed to a postulated population decline in Switzerland over the past 50 years, and led to the classification of the species as potentially endangered in Switzerland in 2003 (Zaugg et al. 2003).

In this study, we use microsatellite markers to investigate the genetic structure of bullhead populations at a spatial scale encompassing a single river and its tributaries.
Our study system, the Sense river and its tributaries, is morphologically very diverse, and fragmented and unfragmented stretches can be directly compared. The headwaters and the lower reaches are heavily fragmented by bed drops and ramps while the mid-section is continuous over ca. $25 \mathrm{~km}$ and represents one of the most natural river habitats in Switzerland. Specifically, we investigate how long-term rates of gene flow, current migration and neutral genetic diversity are affected by dispersal barriers and how these effects differ from those of geographical distance alone.

\section{Materials and methods}

Study area and sampling

Our study river, the Sense, has a very diverse morphology including natural but also canalized and fragmented stretches. With one exception, all barriers within the system are man-made drops in the river bed level in effort to reduce the slope and water velocity, and thereby the impact of flooding events. The height of these man-made barriers is between 0.4 and $2 \mathrm{~m}$. The only natural barrier is a single waterfall, which lies at the confluence of a tributary and the main channel. The two headwater arms, the Kalte and Warme Sense, are fragmented by multiple barriers constructed from 1917 onwards (Fig. 1). The mid-section of the main channel, in contrast, represents one of the longest stretches of unfragmented river habitat in Switzerland. The lower reaches down to the confluence with the Saane river are heavily canalized and, again, fragmented by drops and ramps. Since the ramps are probably passable by bullheads they are not shown on the map.

We sampled a total of 15 sites within the main channel of the Sense (including the Warme and Kalte Sense, see Fig. 1), two sites in a large tributary, the Schwarzwasser, and eight sites in smaller tributaries. Bullheads were absent from all small tributaries that were separated from the main river by barriers (indicated by black dots in Fig. 1). At all other sites, we caught bullheads by sampling a $200 \mathrm{~m}$ stretch using a backpack electroshocker (EFKO 1.5KW). Fin clips were stored in 100\% ethanol, and all animals were released at their capture sites. Until processing, the tissue samples were kept in a freezer at $-21^{\circ} \mathrm{C}$. The sample size per site ranged between 12 and 37 individuals (Table 1).

\section{Genotyping}

DNA was extracted with a Qiagen ${ }^{\circledR}$ Bio Sprint 96 DNA Blood Kit (384) extraction robot according to the manufacturer's instructions and each fish was genotyped at 10 microsatellite loci selected from the literature: Cgo33ZIM, 
Fig. 1 Sampling sites in the Sense river and its tributaries, and structure results for $K=3$. Black bars symbolize one or several impassable barriers for which the year of construction is indicate sites where we did not find bullheads indicated if known. Black dots

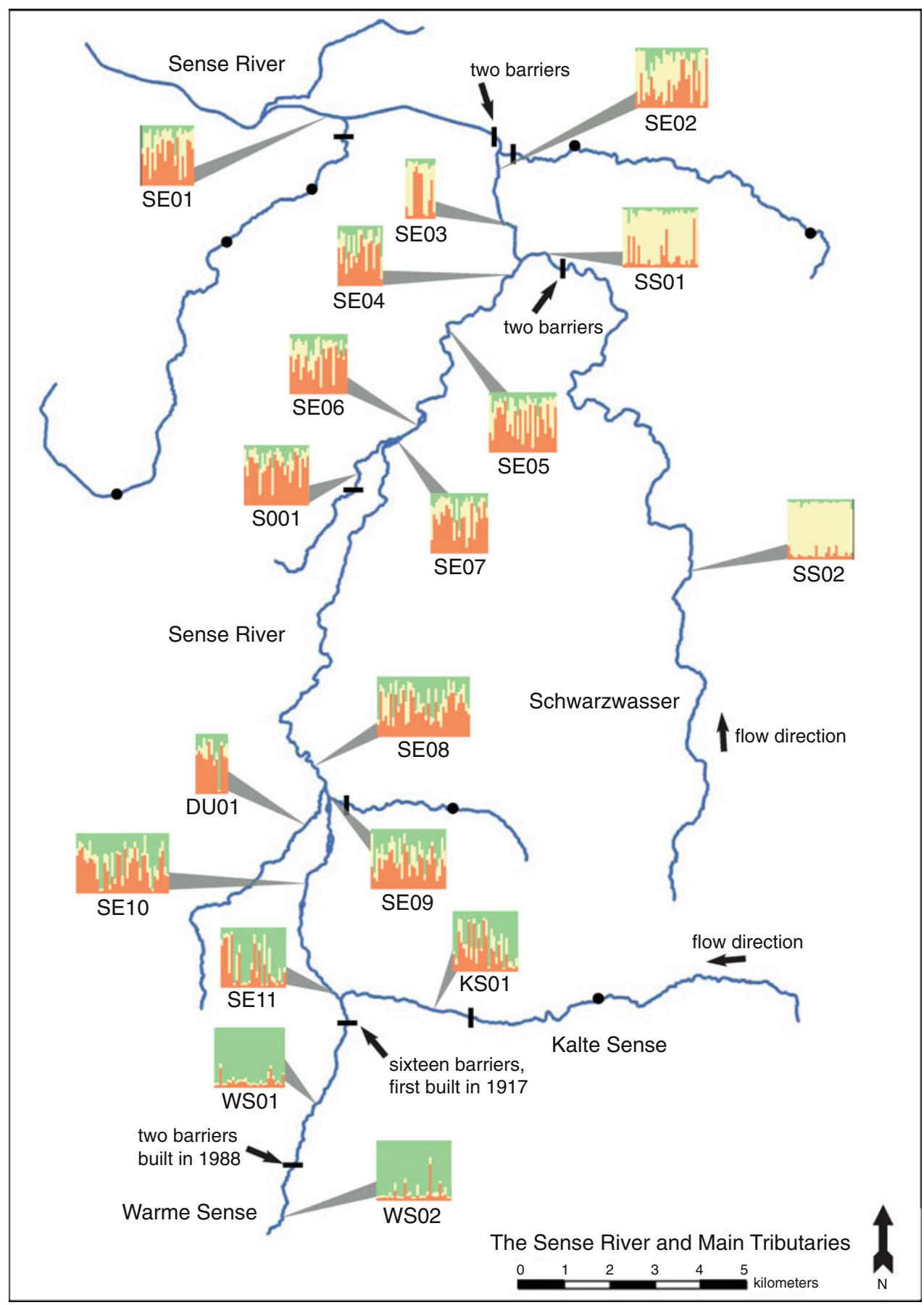

Cgo18ZIM, Cgo1033PBBE, Cgo42ZIM, Cgo34ZIM, Cgo1114PBBE, Cgo56MEHU (Englbrecht et al. 1999), CottE10, Cott687, Cott179 (Nolte et al. 2005b). The forward primers were labeled using three different fluorescent dyes and the primers were divided into two multiplex mixes (for details see Table S1). The PCR amplification was accomplished in a reaction volume of $12.5 \mu \mathrm{l}$ containing $1.25 \mu \mathrm{l}$ primer mix and $6.25 \mu \mathrm{l}$ Qiagen ${ }^{\circledR}$ Multiplex mastermix. The PCR was performed with a Techne TC-412 thermocycler. The PCR cycling protocol for the first multiplex was composed of an initial denaturation for $15 \mathrm{~min}$ at $95^{\circ} \mathrm{C}$, followed by 35 cycles with $30 \mathrm{~s}$ at $94^{\circ} \mathrm{C}$, $90 \mathrm{~s}$ at $58^{\circ} \mathrm{C}, 60 \mathrm{~s}$ at $72^{\circ} \mathrm{C}$ and a final extension of $10 \mathrm{~min}$ at $60^{\circ} \mathrm{C}$. The same protocol was used for the second multiplex but with an annealing temperature of $55^{\circ} \mathrm{C}$. The PCR products were diluted 1:20 for multiplex 1 and 1:50 for multiplex 2 and run on a Beckman Coulter ${ }^{\circledR}$ CEQ 8000 sequencer. We scored alleles with GeneMarker ${ }^{\circledR}$ Version 1.85 (Kellander et al. 2002), and checked each genotype by eye to detect miscalled peaks. 
Table 1 Sampling sites, number of individuals $(n)$ and measures of genetic diversity

$H_{o}$ mean observed

heterozygosity across loci, $H_{e}$ mean expected heterozygosity across loci, $A_{R}$ meanallelic richness, $A_{N}$ mean number of alleles across loci, $F_{I S}$ inbreeding coefficient, $H W D$ loci showing a significant deviation from HWE after Bonferroni correction within populations ( $\alpha=0.005)$; nLD, pairs of loci showing significant linkage disequilibrium at $P<0.001$

\begin{tabular}{lllllllll}
\hline Sampling site & $n$ & $H_{\mathrm{o}}$ & $H_{\mathrm{e}}$ & $A_{\mathrm{R}}$ & $A_{\mathrm{N}}$ & $F_{\text {IS }}$ & HWD & nLD \\
\hline SE01 & 21 & 0.577 & 0.580 & 4.8514 & 5.8 & 0.030 & Cgo56 & - \\
SE02 & 29 & 0.559 & 0.561 & 4.4511 & 5.5 & 0.022 & - & - \\
SE03 & 12 & 0.533 & 0.542 & 4.3 & 4.3 & 0.060 & Cgo56 & - \\
SS01 & 30 & 0.500 & 0.504 & 3.9469 & 4.7 & 0.024 & Cgo18, Cgo33 & - \\
SE04 & 18 & 0.552 & 0.538 & 4.7309 & 5.6 & 0.003 & - & - \\
SE05 & 27 & 0.568 & 0.573 & 4.3544 & 5.6 & 0.028 & Cgo56 & 2 \\
SE06 & 23 & 0.571 & 0.566 & 4.5134 & 5.4 & 0.012 & - & - \\
SE07 & 23 & 0.574 & 0.565 & 4.7039 & 5.9 & 0.007 & - & - \\
SO01 & 26 & 0.615 & 0.590 & 4.8895 & 6.0 & -0.023 & Cgo56 & - \\
SE08 & 37 & 0.575 & 0.548 & 4.5046 & 6.0 & -0.037 & Cg056 & - \\
SE09 & 30 & 0.563 & 0.553 & 4.4904 & 5.7 & -0.001 & - & - \\
DU01 & 13 & 0.569 & 0.553 & 4.2975 & 4.4 & 0.010 & - & - \\
SE10 & 37 & 0.516 & 0.512 & 4.1787 & 5.7 & 0.006 & - & - \\
SE11 & 26 & 0.437 & 0.474 & 3.9027 & 5.0 & 0.097 & Cgo33 & - \\
KS01 & 26 & 0.453 & 0.484 & 3.9361 & 5.1 & 0.084 & Cgo18, Cgo56 & - \\
WS01 & 28 & 0.357 & 0.376 & 2.9922 & 3.5 & 0.068 & - & - \\
WS02 & 30 & 0.407 & 0.393 & 2.7997 & 3.2 & -0.018 & - & - \\
SS02 & 26 & 0.466 & 0.464 & 3.6003 & 4.5 & 0.016 & - & - \\
\hline & & & & & & & & -
\end{tabular}

Statistical analyses

GENEALEX $6^{\circledR}$ was used to calculate the observed and expected heterozygosities and to test for deviations from Hardy-Weinberg equilibrium for all loci and samples (Peakall and Smouse 2006). We tested for deviations from linkage equilibrium between all pairs of loci in all samples using ARLEQUIN 3.11 (Excoffier et al. 2005). The fixation indices, $\mathrm{F}_{\mathrm{IS}}$ and $\mathrm{F}_{\mathrm{ST}}$, were calculated in FSTAT version 2.9.3.2 (Goudet 1995) and ARLEQUIN 3.11, respectively.

We investigated spatial patterns of within-sample genetic diversity based on allelic richness calculated in FSTAT and expected heterozygosity calculated in Arlequin. We measured the distance of each sampling site from the confluence between the Sense and Saane rivers in Google Earth. With this data, we performed a linear regression in SPSS Statistics 17.0. We conducted a second analysis based only on the samples from the continuous river section (SE02-KS01) to exclude the effect of isolated and potentially small populations.

To determine whether there are genetically distinguishable groups at this geographic scale, we analyzed the data in STRUCTURE 2.3 using the admixture model with correlated allele frequencies among populations (Pritchard et al. 2000). We ran analyses for a number of groups $(K)$ of one to five, and performed ten independent runs per $K$ value. The burn-in was set at 100,000 and the number of steps in the Monte Carlo Markov chain was 1,000,000. To select the optimal $K$, we plotted the posterior probability of each run $(\operatorname{LnP}(\mathrm{D}))$ as a function of $K$, as recommended by Pritchard et al. (2000). We then calculated pairwise $F_{\text {ST }}$ values between clusters identified through STRUCTURE analyses using Weir and Cockerham's (1984) estimator in Genodive (Meirmans and Van Tienderen 2004), after excluding individuals that were not assigned $>50 \%$ to a single cluster.

The global analysis revealed genetically distinct clusters in two tributaries, the Warme Sense and Schwarzwasser, and some evidence for demographic admixture at the sites below the inflow into the Sense main channel (see below; Fig. 1). To investigate these patterns in more detail, additional STRUCTURE analyses were carried out on reduced datasets (settings as above except for $K=1-2,5$ runs/K). For the Schwarzwasser, the analysis was based on the sampling sites SE02, SE03, SS01 and SS02, and the analysis for the Warme Sense included sampling sites SE08 to SE11 and both WS samples.

We also investigated if the observed genetic structure around these two confluences could potentially be caused by the presence of closely related individuals (see e.g., Hansen et al. 1997; Anderson and Dunham 2008). We used COLONY version 2.0.1.4 (Jones and Wang 2010) to test for the presence of family groups in a subset of our samples, including all potentially isolated headwater sites. Two replicate analyses were performed on each sample with medium run length, assuming polygamy in both sexes and no inbreeding. Individuals were considered to be closely 
related if they had a probability of being full-sibs $\geq 0.9$ in both replicates. We then reassessed the local genetic structure around the two confluences (Schwarzwasser/ Sense, Kalte/Warme Sense) by repeating the structure analyses on datasets containing only one randomly selected member of each pair or group of full-sibs.

To visualize the genetic relationships among the samples, a neighbour-joining tree was constructed in NEIGHBOUR based on Cavalli-Sforza chord distances $D_{c}$ (Cavalli-Sforza and Edwards 1967) calculated in GENDIST in the PHYLIP 3.65 package (Felsenstein 1993). Node support was assessed based on 1,000 bootstrap replicates.

To test for isolation by distance (IBD), we used Mantel tests (Mantel 1967) of pairwise $F_{\mathrm{ST}}$ values and pairwise geographic distances, with distance measured along the course of the river in Google Earth. In a second Mantel test, we investigated the association between pairwise $F_{\mathrm{ST}}$ values and the number of barriers between all pairs of sites. Finally, we conducted partial Mantel tests based on all three matrices to assess the partial correlation between $F_{\mathrm{ST}}$ and the number of barriers with geographic distance accounted for and, secondly, between $F_{\mathrm{ST}}$ and geographic distance with the number of barriers accounted for. All tests were done with the ECODIST package in $\mathrm{R}$ ( $\mathrm{R}$ Development Core Team 2010), and significance was assessed based on 10,000 permutations (Rousset 1997; Goslee and Urban 2007).

Finally, we used the program BAYESASS 1.3 (Wilson and Rannala 2003) to assess recent migration rates and the direction of migration between sites. The analysis was limited to population pairs showing significant genetic differentiation. To increase sample sizes such that we could use this method on a larger set of samples, we pooled individuals from nearby sites that did not have pairwise $F_{\mathrm{ST}}$ values greater than 0.02 . Using this approach, all populations we assessed in BAYESASS consisted of more than 20 individuals, a size that simulation studies show give accurate estimates of migration parameters (Faubet et al. 2007). The comparisons included sites from the connected river stretch at different geographical scales (17.0 km: SE06/SE07 vs SE11/KS01; 3.3 km: SE09/SE10 vs SE11/KS01; $0.5 \mathrm{~km}: \mathrm{SE02/SE03} \mathrm{vs} \mathrm{SS01)} \mathrm{and} \mathrm{sites}$ separated by barriers (SE10/SE11/KS01 vs WS01/WS02). The following settings were chosen: 3,000,000 iterations, of which 999,999 were burn-in. After the burn-in, every 2,000 th iteration was sampled. The delta values, which specify the maximum amount by which parameter values are allowed to change between iterations, were 0.1 for the allele frequencies, between 0.025 and 0.05 for the migration rate and 0.15 for the inbreeding value. These values were selected based on pilot runs to produce acceptance rates between 40 and $60 \%$, as recommended in the manual.

\section{Results}

In total, there were 10 cases where loci deviated significantly from Hardy-Weinberg equilibrium. These cases were distributed over eight samples and six times involved the locus Cgo56. Two pairs of loci showed significant linkage disequilibrium in sample SE05 (Table 1). We found elevated $F_{\text {IS }}$ values $(\geq 0.06)$ in samples SE03 and SE11, which were collected below the confluences of Sense/Schwarzwasser and Kalte/Warme Sense, respectively, and also in samples WS01 and KS01. None of these values remained significant after Bonferroni correction.

In the full dataset, we observed a significant decrease in allelic richness $\left(R^{2}=0.435, P=0.003\right)$ and a significant decrease in expected heterozygosity $\left(R^{2}=0.434\right.$, $P=0.002$ ) from downstream to upstream sites (Fig. 2a, b). The same trends were observed in the $28 \mathrm{~km}$ long unfragmented stretch but the association was no longer significant for allelic richness $\left(R^{2}=0.198, P=0.111\right)$ and borderline significant for expected heterozygosity $\left(R^{2}=0.284, P=0.05\right)$.

The STRUCTURE analysis strongly supported the presence of three distinct genetic clusters whose distribution showed a clear geographical pattern (Fig. 1). One cluster (green in Fig. 1) was dominant in the Warme Sense, and a second (yellow in Fig. 1) was associated with the Schwarzwasser. Both of these clusters were also observed in the Sense main channel where their frequency gradually decreased with distance from the respective tributary. A third cluster was observed at variable frequencies in the main channel and other smaller tributaries (orange in Fig. 1). The genetic distances between the three clusters are $F_{\mathrm{ST}}=0.088,0.089$ and 0.254 for comparisons of groups orange-yellow, orange-green, and yellow-green, respectively (all $P<0.001$ ), with 65 individuals that did not have $>50 \%$ assignment to a single genetic group excluded from calculations.

In both analyses based on reduced datasets spanning two large tributaries and their inflow into the Sense main channel, STRUCTURE results indicated the presence of two distinct genetic clusters. In general, individuals from tributary sites had high percentages of inferred ancestry to one of these genetic groups, while the individuals from main channel sites were assigned with high percentages to both genetic groups. Specifically, in the two samples from the Warme Sense, WS01 and WS02, 51 out of 58 individuals were assigned to the same cluster with inferred ancestry $\geq 75 \%$ (Fig. 3a). The genotype distribution in sample SE11 (directly below the confluence of the two headwaters) appeared bimodal: individuals were either assigned to cluster 1 or cluster 2 and few were intermediate (Fig. 3a). The genetic transition between Schwarzwasser and Sense main channel was less clear-cut (Fig. 3b) but, 

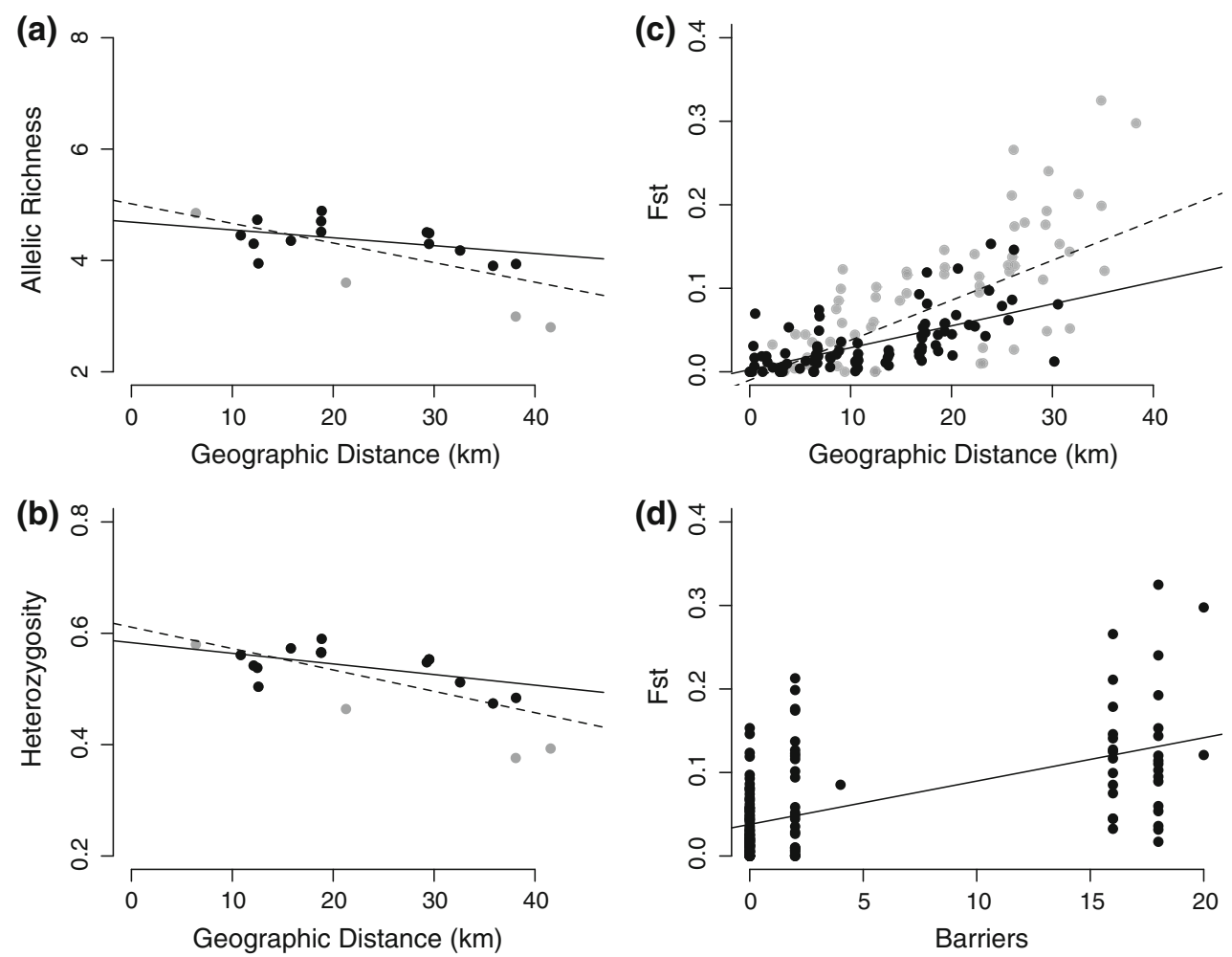

Fig. 2 a Mean allelic richness and b expected heterozygosity as a function of distance from the confluence of the Sense and Saane rivers. Sites without intervening barriers are indicated in black. Separate regression lines are shown for the full dataset (dashed line) and based on the sites from the unfragmented river section (solid line). Both heterozygosity and allelic richness decrease towards the river headwaters, consistent with a scenario of greater downstream than upstream migration. Panels $\mathbf{c}$ and $\mathbf{d}$ show genetic distance (as

again, the populations downstream of the confluence contained a number of individuals with a high percentage of their inferred ancestry ( $\geq 75 \%)$ in the cluster more common in the tributary (25\% in SE03; $10 \%$ in SE02). After excluding closely related individuals ( $0-3$ individuals/site), STRUCTURE analyses still supported the presence of two genetic clusters around the two confluences (Fig. S1).

The neighbour-joining tree showed genetic substructure that was fully consistent with the STRUCTURE results (Fig. 4). One highly-supported clade contained the samples from the Warme Sense together with two nearby sites (KS01 and SE11, see Fig. 1). A second clade with $97 \%$ bootstrap support included the two Schwarzwasser samples and two Sense samples from directly below the inflow of this tributary (SE02, SE03). All remaining samples from the Sense main channel and smaller tributaries grouped together.

The level of pairwise genetic differentiation as measured by $F_{\mathrm{ST}}$ ranged from non-significant to a maximum of 0.32 between two sites separated by about $35 \mathrm{~km}$ (Table 2). The Mantel tests showed a highly significant pattern of isolation by river distance $(r=0.71, P=0.0001$; Fig. $2 \mathrm{c})$ and a highly significant positive association between genetic

$\left.F_{\mathrm{ST}}\right)$ on the y-axis and geographic distance (c) or number of barriers between sites (d) on the x-axis. c $F_{\mathrm{ST}}$ increases with geographic distance between sites, supporting an isolation-by-distance pattern. Black dots are sites without intervening barriers; the dashed line is the relationship between genetic and geographic distance for this subset of populations. Isolation-by-distance patterns are evident for both the complete dataset and the subset of sites without intervening barriers. d $F_{\text {ST }}$ also increases with the number of barriers present between sites

distance and the number of barriers between sites $(r=0.56, P=0.001$; Fig. $2 \mathrm{~d}$ ). Two approaches were used to disentangle the effects of these two explanatory variables, geographic distance and number of barriers, which were themselves significantly positively correlated (Mantel test, $r=0.38, P=0.0001$ ). First, we excluded the influence of barriers by restricting the analysis to samples from the unfragmented river section (SE02 to KS01), which still resulted in a highly significant pattern of isolation by distance ( $r=0.63, P=0.0001$; Fig. 2c). Second, results of a partial Mantel test, including all sites, indicated a significant effect of barriers on divergence even when geographic distance was accounted for $\left(\mathrm{F}_{\mathrm{ST}} \sim\right.$ barriers + distance: mantel $r=0.50$, mantel $P=0.0046$ ). Likewise, when we controlled for the effect of barriers in a partial Mantel test, geographic distance remained a significant predictor of population divergence $\left(F_{\mathrm{ST}} \sim\right.$ distance + barriers: mantel $r=0.61$, mantel $P=0.0001)$. These results indicate that there is significant genetic IBD among sites, even over short geographic distances, and that man-made barriers additionally contribute to the magnitude of isolation observed between samples. 


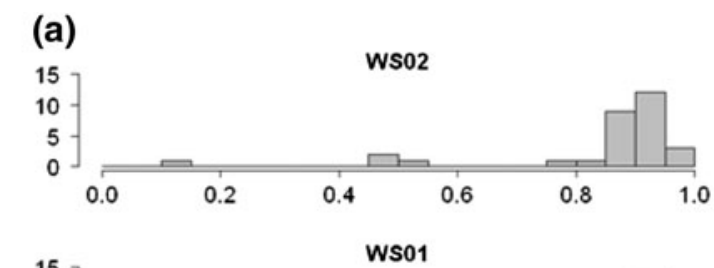

\section{(b)}
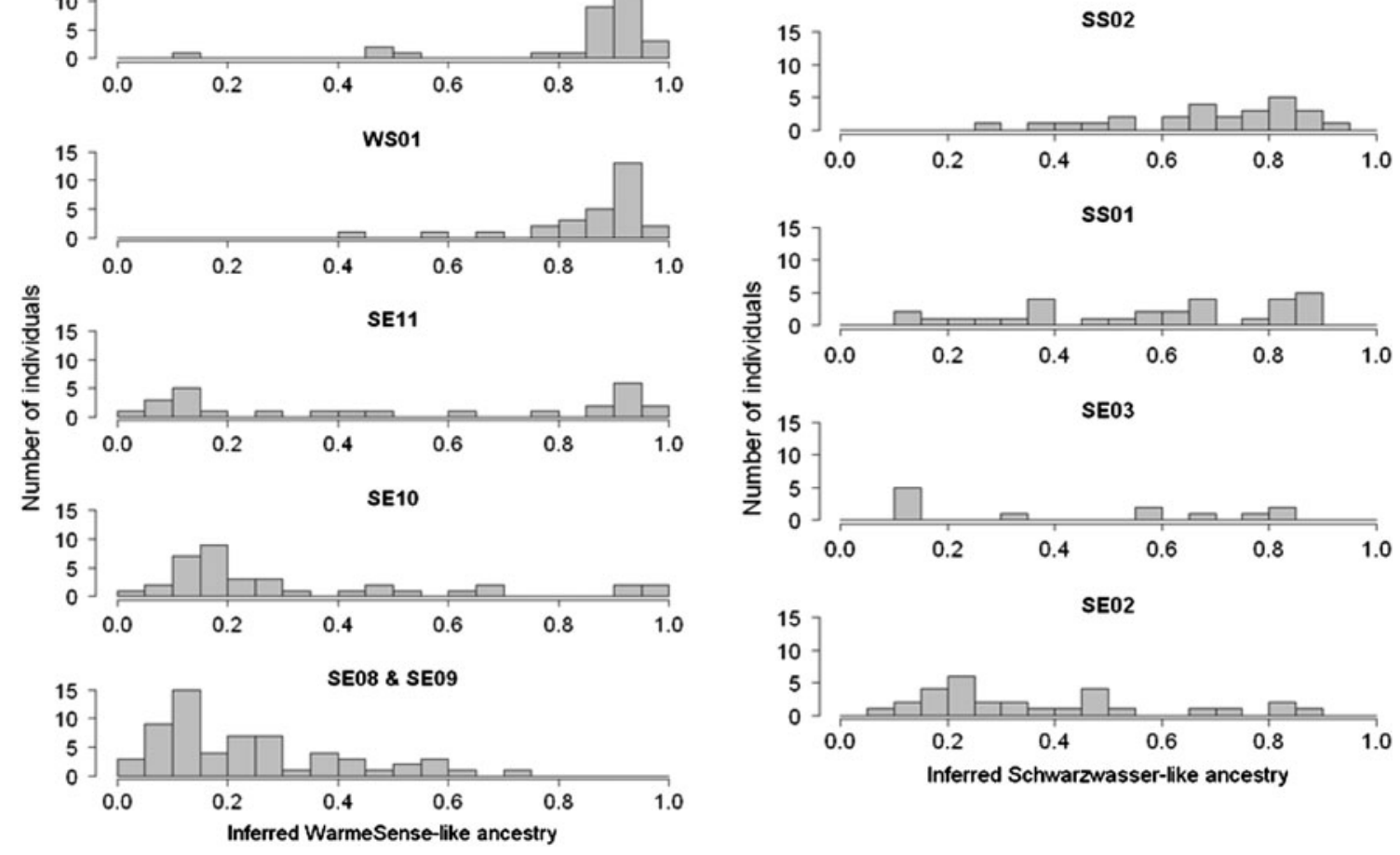

Fig. 3 Distribution of inferred ancestry proportions for individuals from a the Warme Sense and the Sense main channel below the confluence of Kalte and Warme Sense (sites WS01, WS02 and SE08SE11), and $\mathbf{b}$ the Schwarzwasser and the Sense main channel below the inflow of the Schwarzwasser (sites SE02, SE03, SS01, SS02). In both cases, STRUCTURE supported the presence of two genetic

The results from BayesAss suggested considerably stronger downstream than upstream migration (Table 3). The lowest rate of upstream movement was between the sites SE10/SE11/KS01 and WS01/WS02, which are separated by barriers, while the downstream migration rate was comparable to that observed between sites with no barriers between them. Within the continuous river stretch, the rate of downstream migration seemed independent of distance, whereas upstream migration was highest between the two close sites (distance $0.5 \mathrm{~km}$ ) and considerably lower in the other two comparisons (distances 3.3 and $17.0 \mathrm{~km}$ ). It should be noted, however, that we could not include all possible source populations in the analyses, and it is unclear how this could affect the estimates (Wilson and Rannala 2003).

\section{Discussion}

High genetic differentiation at a small geographical scale

Tagging experiments with C. gobio and other Cottus species have shown that bullheads are often fairly

groups. In a we show the number of individuals with a given inferred ancestry in the genetic cluster dominant in the Warme Sense (roughly corresponding to green cluster in Fig. 1), and in $\mathbf{b}$ the number of individuals with a given inferred ancestry in the genetic cluster dominant in the Schwarzwasser (roughly corresponding to yellow cluster in Fig. 1)

resident, moving only up to a few $100 \mathrm{~m}$ per year (Downhower et al. 1990; Knaepkens et al. 2004a). However, movements of $5 \mathrm{~km}$ per year over several years in a row have been documented during range expansions (Nolte et al. 2005a). Consistent with these observations, previous population genetic studies on larger geographic scales detected either very strong genetic differentiation between populations, with $F_{\text {ST }}$ values of up to 0.7 (Nolte et al. 2005a; Hänfling and Weetman 2006; Vonlanthen et al. 2007), or rather little differentiation even over very large distances after a recent invasion (Nolte et al. 2005a). Our data for $C$. gobio in an Alpine river system reveal that strong population genetic differentiation exists at small geographical scales. Between our two genetically most distinct samples, WS01 and SS02, separated by $34.8 \mathrm{~km}$, we observe an $F_{\mathrm{ST}}$ of 0.32 . These two sites are almost certainly not connected by current gene flow because migration between them would involve the crossing of barriers in an upstream direction. However, even if we consider only the samples from our longest unfragmented river stretch, we still observe $F_{\mathrm{ST}}$ values as high as 0.08 at a scale of $30.5 \mathrm{~km}$ (Fig. 1; Table 2). 
Strongly asymmetric dispersal along the river continuum

The observed genetic differentiation suggests that gene flow between these sites is often low. We further find that

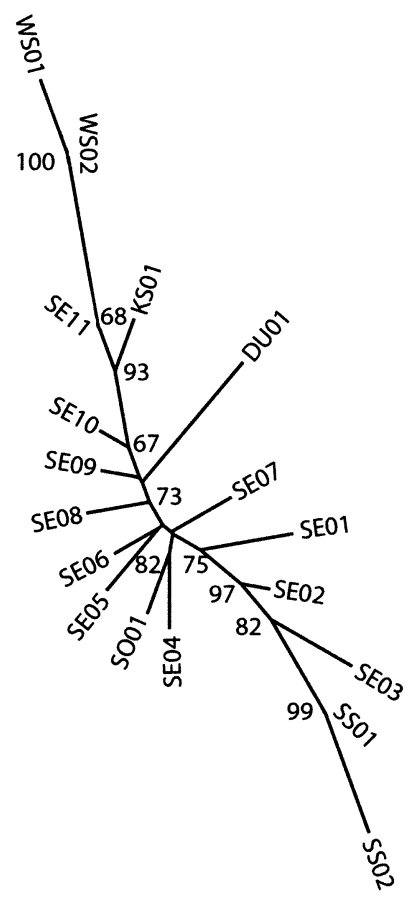

Fig. 4 Unrooted neighbour-joining tree based on Cavalli-Sforza chord distances $\left(D_{C}\right)$. Bootstrap values above $60 \%$ are indicated. Site identifiers correspond to Fig. 1 downstream dispersal is typically greater than upstream dispersal, although the extent of this asymmetry may depend on spatial scale. Estimates of downstream movement rates are consistently high between all examined sites, while the frequency of upstream migrants appears to increase with geographical proximity (Table 3 ). In fact, the asymmetry disappears completely at the smallest geographical scale: BAYESASS shows similar movement rates in both directions between the Schwarzwasser (sample SS01) and the Sense River (samples SE02/03; Table 3). However, it is unclear how reliable these estimates are in this particular comparison because it involves samples that appear demographically admixed (see below). Our results support evidence from other studies investigating the symmetry of movements within rivers which have generally found dispersal to be higher in the direction of water flow than against it. Such a pattern has been shown for bullheads (Hänfling et al. 2002; Hänfling and Weetman 2006) but also for other fishes and aquatic organisms (e.g., Müller 1954; Waters 1972; Caldera and Bolnick 2008). It seems likely that some individuals are passively transported downstream by the current. Such a scenario seems particularly probable for bullhead eggs and larvae which are commonly found in samples from the water column (Peterka et al. 2004).

Barriers amplify gene flow asymmetry and accentuate the loss of genetic diversity in headwaters

Barriers appear to further amplify the dispersal asymmetry: while upstream dispersal may be completely prevented, the

Table 2 Pairwise $F_{\text {ST }}$ values between bullhead samples (below diagonal)

\begin{tabular}{|c|c|c|c|c|c|c|c|c|c|c|c|c|c|c|c|c|c|c|}
\hline & SE01 & SE02 & SE03 & SS01 & SE04 & SE05 & SE06 & SE07 & SO01 & SE08 & SE09 & DU01 & SE10 & SE11 & KS01 & WS01 & WS02 & $\mathrm{SS} 02$ \\
\hline SE01 & & - & - & + & - & - & - & - & - & + & - & + & + & + & + & + & + & + \\
\hline SE02 & 0 & & - & + & + & - & + & - & + & + & + & + & + & + & + & + & + & + \\
\hline SE03 & 0.01 & 0 & & - & + & - & + & - & + & + & + & + & + & + & + & + & + & + \\
\hline SS01 & 0.03 & 0.01 & 0.02 & & + & + & + & + & + & + & + & + & + & + & + & + & + & - \\
\hline SE04 & 0.01 & 0.02 & 0.03 & 0.07 & & - & - & - & - & + & + & + & + & + & + & + & + & + \\
\hline SE05 & 0 & 0 & 0.01 & 0.05 & 0 & & - & - & - & + & + & + & + & + & + & + & + & + \\
\hline SE06 & 0 & 0.02 & 0.03 & 0.07 & 0 & 0 & & - & - & - & - & - & - & + & + & + & + & + \\
\hline SE07 & 0 & 0.01 & 0.01 & 0.05 & 0 & 0 & 0 & & - & + & + & + & + & + & + & + & + & + \\
\hline SO01 & 0 & 0.02 & 0.03 & 0.07 & 0 & 0 & 0 & 0 & & + & + & + & + & + & + & + & + & + \\
\hline SE08 & 0.01 & 0.03 & 0.05 & 0.09 & 0.02 & 0 & 0 & 0.01 & 0.01 & & - & + & - & + & + & + & + & + \\
\hline SE09 & 0.01 & 0.02 & 0.05 & 0.08 & 0.01 & 0 & 0 & 0.01 & 0.01 & 0 & & - & - & + & + & + & + & + \\
\hline DU01 & 0.03 & 0.04 & 0.06 & 0.12 & 0.03 & 0.02 & 0.01 & 0.03 & 0.02 & 0.02 & 0.01 & & + & - & + & + & + & + \\
\hline SE10 & 0.03 & 0.06 & 0.07 & 0.12 & 0.02 & 0.02 & 0.01 & 0.02 & 0.02 & 0.01 & 0 & 0.02 & & - & + & + & + & + \\
\hline SE11 & 0.05 & 0.08 & 0.08 & 0.15 & 0.04 & 0.04 & 0.03 & 0.04 & 0.04 & 0.02 & 0.01 & 0.02 & 0 & & - & + & + & + \\
\hline KS01 & 0.05 & 0.08 & 0.09 & 0.15 & 0.06 & 0.05 & 0.05 & 0.06 & 0.06 & 0.02 & 0.02 & 0.04 & 0.01 & 0 & & + & + & + \\
\hline WS01 & 0.14 & 0.18 & 0.21 & 0.27 & 0.13 & 0.14 & 0.12 & 0.15 & 0.12 & 0.08 & 0.07 & 0.1 & 0.04 & 0.03 & 0.04 & & - & + \\
\hline WS02 & 0.12 & 0.15 & 0.19 & 0.24 & 0.11 & 0.12 & 0.09 & 0.11 & 0.1 & 0.06 & 0.05 & 0.09 & 0.03 & 0.02 & 0.04 & 0 & & + \\
\hline $\mathrm{SS} 02$ & 0.08 & 0.04 & 0.06 & 0.01 & 0.12 & 0.1 & 0.12 & 0.09 & 0.12 & 0.14 & 0.13 & 0.17 & 0.18 & 0.21 & 0.2 & 0.32 & 0.3 & \\
\hline
\end{tabular}

$(+)$ Indicate values significantly different from zero $(P<0.05$; above diagonal $)$ 
Table 3 Proportion of residents (in italic) and recent immigrants (regular font) between four population pairs inferred in BayesAss

\begin{tabular}{|c|c|c|c|c|c|}
\hline & \multicolumn{2}{|l|}{ Migration into } & \multirow[b]{2}{*}{$\begin{array}{l}\text { Genetic } \\
\text { distance }\left(F_{\mathrm{ST}}\right)\end{array}$} & \multirow[b]{2}{*}{$\begin{array}{l}\text { Geographic } \\
\text { distance }(\mathrm{km})\end{array}$} & \multirow[b]{2}{*}{$\begin{array}{l}\text { Physical } \\
\text { barriers }\end{array}$} \\
\hline & pop SS01 & pops SE02/03 & & & \\
\hline \multicolumn{6}{|l|}{ Migration from } \\
\hline pop SS01 & $0.69(0.67,0.7)$ & $\downarrow 0.22(0.11,0.29)$ & 0.01 & 0.5 & No \\
\hline pops SE02/03 & $\uparrow 0.31(0.26,0.33)$ & $0.78(0.71,0.8)$ & & & \\
\hline & pop SE11/KS01 & pop SE09/10 & & & \\
\hline pop SE11/KS01 & $0.96(0.91,1)$ & $\downarrow 0.33(0.31,0.33)$ & 0.01 & 3.3 & No \\
\hline pop SE09/10 & $\uparrow 0.04(0.00,0.09)$ & $0.67(0.67,0.6)$ & & & \\
\hline & pops SE11/KS01 & pops SE06/SE07 & & & \\
\hline pops SE11/KS01 & $0.98(0.94,1)$ & $\downarrow 0.31(0.24,0.33)$ & 0.04 & 17.0 & No \\
\hline pops SE06/SE07 & $\uparrow 0.02(0.00,0.06)$ & $0.70(0.67,0.75)$ & & & \\
\hline & pops WS01/02 & pops SE10/11/KS01 & & & \\
\hline pops WS01/02 & $0.99(0.98,1)$ & $\downarrow 0.31(0.28,0.33)$ & 0.03 & 2.5 & Yes \\
\hline pops SE10/11/KS01 & $\uparrow 0.01(0.00,0.02)$ & $0.68(0.67,0.72)$ & & & \\
\hline
\end{tabular}

The $95 \%$ confidence intervals for all estimates are given in parentheses. Genetic and geographic distances between the sites or pools of sites are indicated. $\downarrow$ Proportion of immigrants from upstream population. $\uparrow$ Proportion of immigrants from downstream population

Note: geographic distance between pools of samples is measured as the distance between the closest sampling sites of two different pools. All $\mathrm{F}_{\mathrm{ST}}$ values were significantly different from zero $(P<0.05)$

frequency of downstream movements seems very little affected. The BayesAss analysis suggests the absence of upstream migrants between sites WS01/02 and SE10/11/ KS01 (95\% c.i. 0-0.02), while potential downstream migrants are observed at a rate similar to that in the continuous river stretch (Table 3 ). Consistent with a very strong reduction in upstream gene flow, distinct genetic clusters are detected in the Schwarzwasser and the Warme Sense (Fig. 1), two large tributaries separated by multiple river bed drops from the main channel. In both cases, the sites directly below the barriers contain a high proportion of individuals that could be recent immigrants from above (Figs. 1, 3a, b). Finally, the partial Mantel test supports an effect of the number of barriers on genetic differentiation between sites in addition to the effect of geographical distance (Fig. 2d). Similarly, Meldgaard et al. (2003) detected a statistically significant increase of $\mathrm{F}_{\mathrm{ST}}$ with the number of weirs between grayling populations.

In the Warme Sense, where the age of the barriers is known, the observed level of genetic differentiation seems largely consistent with expectations. The first bed drops in the Warme Sense were built ca. 90 years ago, which corresponds to a minimum of 30 generations if we assume a generation time of 2-3 years at this altitude (Elliot 1981). This is the temporal scale investigated by Keller et al. (2004) in computer simulations of genetic divergence between two completely isolated populations of unequal effective size, one large $\left(N_{\mathrm{e}}=10,000\right)$ and one small $\left(N_{\mathrm{e}}\right.$ varied between 50 and $\left.1^{\prime} 000\right)$. Under this scenario, $F_{\mathrm{ST}}$ values consistent with that observed between SE11 and
WS01 $($ mean $=0.033,95 \%$ c.i. $=0.007-0.062) \quad$ were observed in simulations with an effective size for the smaller population of 200-1,000 individuals. Quantitative samples from four stretches in the Warme Sense resulted in estimates of bullhead density of 0.0375 individuals $/ \mathrm{m}^{2}$ (Goldmann, 1993). The water surface of the Warme Sense is about $37,800 \mathrm{~m}^{2}$ which leads to an estimated population size of around 1,400 bullheads. This value almost certainly underestimates the real population size since bullheads are difficult to catch. Still, an effective population size in the order of 200-1,000 does not seem unrealistic for the Warme Sense in view of the fact that $N_{\mathrm{e}}$ can be considerably smaller than the census population size (Frankham 1995), especially in species, like the bullhead, with polygynous mating systems (Bisazza and Marconato 1988).

Populations from the isolated tributaries/headwaters are not only genetically differentiated but also have reduced genetic diversity. While a trend towards reduced allelic richness and heterozygosity at more upstream sites is observed also in the unfragmented habitat, the effect is much more pronounced when the isolated populations from the Warme Sense and Schwarzwasser are included (Fig. 2a, b). This pattern is consistent with a scenario where barriers further amplify the asymmetry of gene flow from upstream towards downstream sites. Additionally, colonisation history may have contributed to the observed decrease of genetic diversity. Genetic diversity may be lost in the course of range expansions (e.g. Excoffier et al. 2009) and, hence, should be lowest in the headwaters if 
these were colonized last. Similar decreases of genetic diversity from downstream towards upstream populations have been observed in other bullhead populations (Hänfling and Weetman 2006) and other fish species (e.g. Yamamoto et al. 2004; Caldera and Bolnick 2008; Raeymaekers et al. 2009).

Together, our results are consistent with a scenario where dispersal barriers interrupt upstream gene flow and lead to the genetic divergence and depletion of isolated populations. However, without samples from unfragmented headwater populations we cannot confidently exclude the possibility that such populations would show different genetic patterns. For example, it seems possible that the bias against upstream dispersal increases with river slope, which could increase isolation of headwater populations even in the absence of man-made barriers.

Headwater populations may be particularly valuable and vulnerable

Irrespective of whether their isolation is mainly due to natural or anthropogenic causes, we can conclude that the Sense tributaries/headwaters harbour bullhead populations that are genetically distinct from those in the main channel. More detailed genetic and ecological analyses of these populations would be of great interest both from an evolutionary and from a conservation perspective. Provided that the genetic depletion in these populations is not too extreme, their isolation could actually have facilitated local adaptation (e.g., Williams et al. 2003). Such populations would then harbor an important component of bullhead adaptive genetic diversity and would potentially need to be treated as independent evolutionarily significant units (ESU) in conservation.

In fact, one observation may be of particular interest in this context: The samples collected directly below the inflows of the large tributaries, SE11 and to a lesser extent SE03, appear to contain two distinct groups of genotypes with few intermediates suggesting demographic admixture between two distinct subpopulations (Fig. 3a, b, see also the respective STRUCTURE bar plots in Fig. 1). Both samples exhibited elevated although statistically not significant $F_{\text {IS }}$ values (Table 1). A pattern of demographic admixture could result if the site directly below the inflow of a tributary (i.e., SE11, SE03) receives many downstream migrants from both river branches. It is currently difficult to judge if immigration rates are indeed high enough to be consistent with such an interpretation, which would also leave the presence of several Warme Sense-like genotypes in site KS01 (green in Fig. 1) unexplained. Alternatively, it is possible that the majority of individuals originate from local reproduction, in which case the observed bimodality in the genotype distribution would suggest assortative mating between tributary and main stream populations.

Tributaries and headwaters may be particularly affected by habitat fragmentation. Isolation and small population size may decrease long-term population viability and adaptive potential and, if local extinctions do occur, a particular habitat may not be recolonized because barriers make upstream migration impossible. Indeed, we found that in the Sense system bullheads were absent from several sampling sites in small tributaries separated from the main channel by impassable barriers (Fig. 1). If indeed many tributaries and headwaters contain bullhead populations with unique genotype composition and, quite possibly, local adaptations, we may currently be experiencing the successive loss of ecological and evolutionary diversity in bullheads as these populations disappear.

Acknowledgments Special thanks go to Christina Riedl, Laura Langeloh and Reto Haas for their valuable help during fieldwork. We thank the local fisheries authorities of Bern and Fribourg for their support of this project. We are also grateful to the members of the River Management project and special thanks go to all the people at Fishec, who have always been very supportive. We would also like to thank E. E. Nielsen and three anonymous reviewers for their valuable input. This project was financially supported by EAWAG through an action field grant to AP and IK.

\section{References}

Adamicka P (1979) Zwei Vorurteile über die Schädlichkeit von Koppen und Kaulquappen. Österreichs Fischerei 32:162-164

Adamicka P (1984) Neues vom 'argen Laichräuber' (Cottus gobio). Österreichs Fischerei 31:334-336

Anderson EC, Dunham KK (2008) The influence of family groups on inferences made with the program Structure. Mol Ecol Resour $8: 1219-1229$

Andreasson S (1971) Feeding habits of a sculpin (Cottus gobio L. Pisces) population. Report of the institute of freshwater research, Drottningholm, Sweden, 51: 5-30

Barandun J (1990) Auswirkungen von ausbreitungsobstruktionen auf das Vorkommen von Groppen (Cottus gobio) - Anregungen für den Artenschutz. Natur und Landschaft 65:66-68

Bisazza A, Marconato A (1988) Female mate choice, male-male competition and parental care in the river bullhead, Cottus gobio L. (Pisces, Cottidae). Anim Behav 36:1352-1360

Bless R (1981) Untersuchungen zum Einfluss von gewässerbaulichen Massnahmen auf die Fischfauna in Mittelgebirgsbächen. Natur und Landschaft 56:243-252

Bless R (1990) Die Bedeutung von gewässerbaulichen Hindernissen im Raum-Zeit-System der Groppe (Cottus gobio L.). Natur und Landschaft 65:581-585

Bucher F, Hofer R, Salvenmoser W (1992) Effects of treated paper mill effluents on hepatic morphology in male bullhead (Cottus gobio L.). Arch Environ Contam Toxicol 23:410-419

Caldera EJ, Bolnick DI (2008) Effects of colonization history and landscape structure on genetic variation within and among threespine stickleback (Gasterosteus aculeatus) populations in a single watershed. Evol Ecol Res 10:575-598 
Cavalli-Sforza LL, Edwards AW (1967) Phylogenetic analysis. Models and estimation procedures. Am J Hum Genet 19:233257

Downhower JF, Lejeune P, Gaudin P, Brown L (1990) Movements of the chabot (Cottus gobio) in a small stream. Polskie Archiwum Hydrobiologii 37:119-126

Elliot JM (1981) Some aspects of thermal tolerance of freshwater teleosts. In: Pickering AD (ed) Stress and fish. Academic Press, UK, pp 209-245

Englbrecht CC, Largiadèr CR, Hänfling B, Tautz D (1999) Isolation and characterization of polymorphic microsatellite loci in the European bullhead Cottus gobio L. (Osteichthyes) and their applicability to related taxa. Mol Ecol 8:1966-1969

Englbrecht CC, Freyhof J, Nolte A, Rassmann K, Schliewen U, Tautz D (2000) Phylogeography of the bullhead Cottus gobio (Pisces: Teleostei: Cottidae) suggests a pre-pleistocene origin of the major central European populations. Mol Ecol 9:709-722

Excoffier L, Laval G, Schneider S (2005) Arlequin (version 3.0): an integrated software package for population genetics data analysis. Evol Bioinformatics 1:47-50

Excoffier L, Foll M, Petit RJ (2009) Genetic consequences of range expansions. Ann Rev Eco Evol Syst 40:481-501

Faubet P, Waples RS, Gaggotti OE (2007) Evaluating the performance of a multilocus Bayesian method for the estimation of migration rates. Mol Ecol 16:1149-1166

Felsenstein J (1993) PHYLIP (Phylogeny Inference Package) version 3.5c. Distributed by the author. Department of Genetics, University of Washington, Seattle

Frankel OH, Soule M (1981) Conservation and Evolution. Cambridge University Press, Cambridge

Frankham R (1995) Effective population size/adult population size ratios in wildlife: a review. Genet Res 66:95-107

Gädtgens A (1989) Die Rolle der Groppe (Cottus gobio L.) als Konsument des Zoobenthos im Ökosystem eines Mittelgebirgsbaches (Steine/Schwarzwald). Diplomarbeit. Fakultät für Biologie der Universität Konstanz 62

Gaudin P (1985) Predation Exercée par le Chabot (Cottus gobio L.) sur I'Alevin de Truite Commune (Salmo trutta 1.): taille maximale de capture des alevins par les chabots. Hydrobiologia 122:267-270

Gaudin P, Caillere L (1990) Microdistribution of Cottus gobio L. and fry of Salmotrutta in a first order stream. Pol Arch Hydrobiol 37:81-93

Gaudin P, Heland M (1984) Influenced'Adultes de Chabots (Cottus gobio L.) sur des Alevins de TruiteCommune (SalmotruttaL.): etude experimentale en milieux semi-naturels. Aria Oecol 5:71-83

Goldmann K (1993) Einfluss von Querbauwerken in einem voralpinen Fliessgewässer auf die Fischpopulationen. Diplomarbeit, Albert-Ludwigs-Universität Freiburg im Breisgau, Fakultät für Biologie

Goslee SC, Urban DL (2007) The ecodist package for dissimilaritybased analysis of ecological data. J Stat Softw 22:1-19

Goudet J (1995) Fstat (Version 1.2): a computer program to calculate F-statistics. J Hered 86:485-486

Hänfling B, Weetman D (2006) Concordant genetic estimators of migration reveal anthropogenically enhanced source-sink population structure in the river sculpin Cottus gobio. Genetics 173:1487-1501

Hänfling B, Hellemans B, Volckaert FAM, Carvalho GR (2002) Late glacial history of the cold-adapted freshwater fish Cottus gobio, revealed by microsatellites. Mol Ecol 11:1717-1729

Hansen MM, Nielsen EE, Mensberg KLD (1997) The problem of sampling families rather than populations: relatedness among individuals in samples of juvenile brown trout Salmo trutta L. Mol Ecol 6:469-474
Hofer R, Bucher F (1991) Zur Biologie und Gefährdung der Koppe. Österreichs Fischerei 44:158-161

Jones OR, Wang J (2010) Colony: a program for parentage and sibship inference from multilocus genotype data. Mol Ecol Resour 10:551-555

Jungwirth M (1996) Bypass channels at weirs as appropriate aids for fish migration in lithoral rivers. Regul Rivers: Res Manag 12:483-492

Kellander M, Riley M, Liu CS (2002) GeneMarker ${ }^{\circledR}$ Software for Multiplex Ligation-dependent Probe Amplification (MLPA ${ }^{\mathrm{TM}}$ )

Keller I, Nentwig W, Largiadèr CR (2004) Recent habitat fragmentation due to roads can lead to significant genetic differentiation in an abundant flightless ground beetle. Mol Ecol 13:2983-2994

Kindlmann P, Burel F (2008) Connectivity measures: a review. Landsc Ecol 23:879-890

Knaepkens G, Knapen D, Bervoets L, Hänfling B, Verheyen E, Eens M (2002) Genetic diversity and condition factor: a significant relationship in Flemish but not in German populations of the European bullhead (Cottus gobio L.). Heredity 89:280-287

Knaepkens G, Bruyndoncx L, Eens M (2004a) Assessment of residency and movement of the endangered bullhead (Cottus gobio) in two Flemish rivers. Ecol Freshw Fish 13:317-322

Knaepkens G, Bruyndoncx L, Coeck J, Eens M (2004b) Spawning habitat enhancement in the European bullhead (Cottus gobio), an endangered freshwater fish in degraded lowland rivers. Biodivers Conserv 13:2443-2452

Letcher BH, Nislow KH, Coombs JA, O’Donnell MJ, Dubreuil TL (2007) Population response to habitat fragmentation in a streamdwelling brook trout population. PLoS ONE 2(11):e1139

Mantel N (1967) The detection of disease clustering and a generalized regression approach. Cancer Res 27:209-220

Meirmans PG, Van Tienderen PH (2004) GENOTYPE and GENODIVE: two programs for the analysis of genetic diversity of asexual organisms. Mol Ecol Notes 4:792-794

Meldgaard T, Nielsen EE, Loeschcke V (2003) Fragmentation by Weirs in a Riverine system: a study of genetic variation in time and space among populations of European grayling (Thymallus thymallus) in a Danish river system. Conserv Genet 4:735747

Müller K (1954) Investigations on the organic drift in North Swedish streams. Inst Freshw Res Rep 34:133-149

Nolte AW, Freyhof J, Stemshorn KC, Tautz D (2005a) An invasive lineage of sculpins, Cottus sp (Pisces, Teleostei) in the Rhine with new habitat adaptations has originated from hybridization between old phylogeographic groups. Proc Royal Soc B 272:2379-2387

Nolte AW, Stemshorn KC, Tautz D (2005b) Direct cloning of microsatellite loci from Cottus gobio through a simplified enrichment procedure. Mol Ecol Notes 5:628-636

Peakall R, Smouse PE (2006) Genalex 6: genetic analysis in excel. Population genetic software for teaching and research. Mol Ecol Notes 6:288-295

Peterka J, Vašek M, Kubečka J, Hladík M, Hohausová E (2004) Drift of juveniles after riverine spawning of fishes from the Rímov reservoir, Czech Republic. Ecohydrol Hydrobiol 4(4):459-468

Pritchard JK, Stephens M, Donnelly P (2000) Inference of population structure using multilocus genotype data. Genetics 155:945-959

Raeymaekers JAM, Raeymaekers D, Koizumi I, Geldof S, Volckaert FAM (2009) Guidelines for restoring connectivity around water mills: a population genetic approach to the management of riverine fish. J Appl Ecol 46:562-571

R Development Core Team (2010) R: a language and environment for statistical computing. $\mathrm{R}$ foundation for statistical computing. Vienna, Austria. http://www.R-project.org

Rosenzweig ML (2001) Loss of speciation rate will impoverish future diversity. Proc Natl Acad Sci USA 98(10):5404-5410 
Rousset F (1997) Genetic differentiation and estimation of gene flow from F-statistics under isolation by distance. Genetics 145:12191228

Sala OE, Stuart Chapin III F, Armesto JJ et al (2000) Global biodiversity scenarios for the year 2100. Science 287(5459): 1770-1774

Segelbacher G, Cushman SA, Epperson BK, Fortin MJ, Francois O, Hardy OJ, Holderegger R, Taberlet P, Waits LP, Manel S (2010) Applications of landscape genetics in conservation biology: concepts and challenges. Conserv Genet 11:375-385

Smyly WJP (1957) The life-history of the bullhead or miller's thumb (Cottus gobio L.). Proc Zool Soc Lond 128:431-453

Späh H, Beisenherz W (1984) Beitrag zur Ökologie und Verbreitung der Groppe (Cottus gobio, Pisces) in Ostwestfalen und in Osnabrück (Niedersachsen). Verh Ges Ökologie 12:617-626

Starmach J (1965) Koppen in den Karpathenflüssen: II. Auftreten und Charakteristik der Buntflossenkoppe (Cottus poecilopus Heckel) und Weissflossigen Koppe (Cottus gobio L.) in Raba Flussgebiet. Acta Hydrobiol 7:109-140

Tudorache C, Viaene P, Blust R, Vereecken H, De Boeck G (2008) A comparison of swimming capacity and energy use in seven European freshwater fish species. Ecol Freshw Fish 17:284-291

Utzinger J, Roth C, Peter A (1998) Effects of environmental parameters on the distribution of bullhead Cottus gobio with particular consideration of the effects of obstructions. J Appl Ecol 35:882-892
Vonlanthen P, Excoffier L, Bittner D, Persat H, Neuenschwander S, Largiader CR (2007) Genetic analysis of potential postglacial watershed crossings in Central Europe by the bullhead (Cottus gobio L.). Mol Ecol 16:4572-4584

Waters TF (1972) Drift of stream insects. Annu Rev Entomol $17: 253-272$

Waterstraat A (1992) Investigations on the ecology of Cottus gobio L. and other fish species from two lowland streams of Northern Germany. Limnologica 22:137-149

Weir BS, Cockerham CC (1984) Estimating F-statistics for the analysis of population structure. Evolution 38:1358-1370

Williams BL, Brawn JD, Page KN (2003) Landscape Scale genetic effects of habitat fragmentation on a high gene flow species: Speyeriaidalia (Nymphalidae). Mol Ecol 12:11-20

Wilson GA, Rannala B (2003) Bayesian inference of recent migration rates using multilocus genotypes. Genetics 163:1177-1191

Yamamoto S, Morita K, Koizumi I, Maekawa K (2004) Genetic differentiation of white-spotted charr (Salvelinus leucomaenis) populations after habitat fragmentation: spatial-temporal changes in gene frequencies. Conserv Genet 5:529-538

Zaugg B, Stucki P, Pedroli JC, Kirchhofer A (2003) Pisces Atlas. Fauna Helvetica 7

Zeh Weissmann H, Könitzer C, Bertiller A (2009) Strukturen der Fliessgewässer in der Schweiz. Zustand von Sohle, Ufer und Umland (Ökomorphologie); Ergebnisse der Ökomorphologischen Kartierung. Stand: April 2009. Umwelt-Zustand Nr. 0926 